\title{
Priming is not necessary for selective-attention failures: Semantic effects of unattended, unprimed letters
}

\author{
JEFF MILLER \\ University of California, San Diego, La Jolla, California
}

\begin{abstract}
Certain experimental effects indicate that unattended stimuli are sometimes processed semantically (e.g., B. A. Eriksen \& C. W. Eriksen, 1974; Stroop, 1935). Previously, such effects have been demonstrated primarily in situations in which the identities of the unattended stimuli would have been primed by task relevance, and it is possible that such priming is necessary for unattended stimuli to be processed semantically. Six experiments examined the importance of such priming in the selective-attention paradigm of Eriksen and Eriksen (1974). Subjects classified target letters presented in the relevant center position of a three-letter visual display, ignoring simultaneously presented irrelevant flanker letters on each side of it. Across trials, identities of the flankers were correlated with, and therefore predictive of, correct responses. Although subjects had been instructed to ignore the flankers and later seemed to have no awareness of their correlation with responses, response times indicated that subjects learned and were influenced by the predictive relationship of the flanker to the response. This effect provides an example of semantic processing of unattended stimuli that have not been primed by either task relevance or long-term relevance. It is also of interest as an example of associative learning that is both incidental and apparently unconscious.
\end{abstract}

Everyone has had the experience of concentrating attention on one of the things he/she sees and ignoring the others. The batter concentrates on the ball in the pitcher's hand, the portrait painter concentrates on the shape of the subject's chin, and, especially on a foggy night, the motorist concentrates on the lines on the highway. Both introspective evidence and results from some experimental paradigms suggest that in such cases the concentration of attention can be so nearly complete that almost nothing is noticed about the unattended objects (James, 1890; Neisser \& Becklen, 1975).

Results of other experimental paradigms, however, indicate that unattended stimuli do influence behavior (e.g., B. A. Eriksen \& C. W. Eriksen, 1974; Kellogg, 1980; Rollins \& Thibadeau, 1973; Stroop, 1935). In a paradigm used by C. W. Eriksen and his associates (e.g., B. A. Eriksen \& C. W. Eriksen, 1974; C. W. Eriksen \& Schultz, 1979), for example, people are presented with a row of letters and asked to concentrate attention on the letter in the center and to ignore simultaneously presented flanker letters on both sides of it. They are instructed to press one response key if the center letter belongs to one set of targets (e.g., A and B) and another response key

\footnotetext{
This research was supported by Grant PHS MH40733 from the National Institute of Mental Health. The idea for these experiments originally took shape in a seminar discussion with Mitchell Rabinowitz and Gregory Stone. I would like to thank William Epstein, C. W. Eriksen, Patricia Haden, John Jonides, Harold Pashler, and the anonymous reviewers for helpful comments on the experiments and their exposition, and Bancroft Dutton for assistance in collecting the data. Requests for reprints should be addressed to the author at Department of Psychology, C-009. UCSD, La Jolla, CA 92093.
}

if the center letter comes from another set of targets (e.g., C and D). Although subjects are instructed to ignore flanker letters, their response times (RTs) show that they cannot do so completely. Specifically, when one of the four target letters appears as a flanker, it speeds the response if it belongs to the same target set as the center letter (e.g., BAB), but it slows the response if it belongs to the opposite target set (e.g., CAC). This so-called "Eriksen effect" shows that flanker letters influence responses not only by their presence, but also by their semantic properties (identities).

The imperfect visual selectivity demonstrated by the Eriksen effect is important evidence in the debate between proponents of early- and late-selection theories of attention (for reviews see, e.g., Egeth, 1967, 1977). This longstanding debate concerns the amount of stimulus processing that takes place before attentional selection occurs. Early-selection theorists argue that only rudimentary feature analysis takes place before attentional selection occurs (e.g., Broadbent, 1958; Kahneman \& Treisman, 1984). For example, in the classic filter theory of Broadbent (1958), crude physical characteristics of the stimuli are determined and then stimuli are selected on the basis of these characteristics. A filter mechanism allows only the selected stimuli to proceed through to the semantic system for further processing, so that unselected stimuli are never processed semantically. A functionally similar theory has been advocated by Neisser (1979), who emphasizes the active nature of the pickup of perceptual information and argues that unattended information does not need to be filtered because it is never picked up by the 
perceptual system. On the other hand, late-selection theorists assert that all stimuli automatically undergo full semantic analysis by the perceptual system (i.e., identification) and that selection takes place only after this analysis is complete (e.g., Deutsch \& Deutsch, 1963; Duncan, 1980; Shiffrin, 1975; Van der Heijden, 1981). They contend that selected stimuli are more likely to enter awareness and to control responses, but that they are not favored in perceptual processing.

The Eriksen effect provides prima facie evidence that even unattended stimuli are identified, so it is regarded as evidence of late rather than early attentional selection (e.g., Posner, 1973; Van der Heijden, 1981), as are some similar effects of the identity of irrelevant information (e.g., Stroop, 1935). ${ }^{1}$ After all, if attentional selection took place before identification, how could responses depend on the identities of unattended stimuli? Indeed, Van der Heijden (1981) has suggested that effects of this type are the most important sources of evidence in deciding between early and late selection:

\begin{abstract}
The question whether Ss can restrict identification to a part of a stimulus, or, can focus attention at the precategorical level, is better answered by looking for effects of irrelevant or unwanted information. That is, if identity-specific effects of unwanted information are found then the irrelevant information must have been processed, and the assumption of precategorical [i.e., early] selection has to be rejected. (p. 82)
\end{abstract}

The experiments reported in this paper were designed to examine the importance of flanker priming in the Eriksen paradigm. In this paradigm, logogens corresponding to target letters would be primed or preactivated (Posner \& Snyder, 1975) by virtue of their status as target letters in the task. Specifically, the question addressed in these experiments was whether such priming is necessary for unattended letters to be identified.

The dependence of the Eriksen effect on flanker priming is worth examining because it is relevant to an attenuation-and-priming model that might be used to reconcile early-selection models with the effect. It could be argued that identity effects of unattended items only rule out models with early, all-or-none attentional selection, not early selection per se (e.g., Broadbent, 1971, 1982; Johnston \& Dark, 1982; Kahneman \& Treisman, 1984). Perhaps the early-selection mechanism does not completely filter out unselected stimuli, in the sense of preventing any subsequent processing of them, but rather attenuates them, reducing their power or salience as inputs to the subsequent semantic processing system. Attenuated stimuli can perhaps still be identified by the semantic system when they are primed (e.g., by task relevance). Such priming might cause the primed logogens to reach threshold, leading to identification responses, even when the logogens receive evidence only from attenuated stimuli (cf. Underwood, 1976). ${ }^{2}$ Once unattended stimuli are identified, of course, their identities could produce response activation that would facili- tate or compete with the activation produced by the center target letter, thereby producing the Eriksen effect (Coles, Gratton, Bashore, C. W. Eriksen, \& Donchin, 1985). Thus, the Eriksen effect can be reconciled with an earlyselection model incorporating the dual assumptions that unselected stimuli are attenuated and that priming can overcome attenuation.

In fact, an early-selection model with attenuation and priming is consistent with most effects of unattended information, because all identity effects of unattended stimuli can plausibly be attributed to priming. The Stroop (1935) effect, like the Eriksen effect, is explained by the task-relevance of the unattended information. Another such effect is that subjects recognize their own names in unattended locations (Wolford \& Morrison, 1980), explainable by the assumption that one's own name has a permanently high relevance. There are also identity effects of unattended letters that have previously been targets in search tasks (Shiffrin \& Schneider, 1977) and of unattended words that have previously been associated with electric shock (Corteen \& Wood, 1972; Dawson \& Schell, 1982; Forster \& Govier, 1978; Govier \& Pitts, 1982). Both of these effects can be explained by the assumption that the training and conditioning operations produce a long-term priming of the relevant stimuli. Unattended words can also have identity effects if they are semantically related to the context provided by an attended message (e.g., Lackner \& Garrett, 1972; Lewis, 1970; MacKay, 1973), and in this case the attended message could provide the necessary priming for the unattended message.

Despite the consistency of the attenuation-and-priming model with effects of unattended stimuli, there is no direct evidence for the assumption that priming is necessary for unattended stimuli to be identified. ${ }^{3}$ Although there have been experiments in which unprimed and unattended stimuli did not produce identity effects (e.g., Neisser \& Becklen, 1975), these were not explicitly concerned with priming and so did not include control conditionslogically necessary in the present context-to show that identity effects would have been obtained if the stimuli had been primed. Similarly, although there are many demonstrations of identity effects of primed, unattended stimuli, there have been no additional conditions showing that these effects disappear when the stimuli are not primed.

The experiments reported in this article were designed as a direct test of the hypothesis that priming is necessary to produce identity effects of unattended stimuli. On each trial, a single relevant target letter was presented in the center of a display and one irrelevant flanker letter was presented on each side of it. In this situation, the Eriksen effect is strong evidence that flankers are identified when their identities are primed by task relevance (i.e., when they are targets). The question addressed by these experiments was whether flanker identification ceases when flankers are not primed by task relevance, as predicted by the attenuation-and-priming model. In these 
experiments, unlike Eriksen's, irrelevant flankers never belonged to either target set, so they were not directly task relevant. These response-neutral flankers should not have been primed, so, according to the attenuation-andpriming model, they should not have been identified.

To see whether the response-neutral flankers were identified, a correlation between flanker identity and correct response was introduced into the stimulus set. Given the presence of any particular flanker, one response was much more likely to be correct than was the other response, as illustrated in Table 1 . Thus, flanker identity could potentially act as a cue to the correct response, with the validity of the cue determined by the strength of the correlation. In Table 1 , for example, the flanker $X$ should cue the left-hand response, and the flanker $Y$ should cue the right-hand response. If the system can take advantage of such cuing, then responses should be faster on the common trials with valid correlational cues (e.g., X flanker and target assigned to left response) than on the rare trials with invalid correlational cues (e.g., X flanker and target assigned to right response).

Early-selection models with attenuation and priming predict that correlational cues should not affect responses. Because the unattended and unprimed flankers would not be identified, the association between flanker identity and correct response would not be learned. Thus, any observed correlational cuing effect would be difficult to reconcile with these models.

Late-selection models, although they need not necessarily predict a correlational cuing effect, would be quite consistent with one. Since flanker identities would automatically be recognized, the association between flanker identity and response could easily be learned and, once learned, could easily influence responses. The learning of covariation is a critical component of many forms of learning, including classical and instrumental conditioning (see Alloy \& Tabachnik, 1984; Bindra, 1972), and it is evident even in the simplest neural systems (Hawkins, 1983). Thus, it seems unlikely that this type of learning would require that stimuli be attended. There is also evidence that some frequency learning occurs with little or no attention in humans (Hasher \& Zacks, 1979, 1984), and it is only a small additional step to suppose that contingency (i.e., conditional frequency) learning can occur also. Finally, a number of experiments have shown that subjects are sensitive to conditional probabilities of unattended stimuli when the unattended stimuli are task-

Table 1

Joint Probabilities of (Flanker Identity, Correct Response) Pairs Illustrating Correlational Cuing

\begin{tabular}{|c|c|c|}
\hline & Flanke & Identity \\
\hline Correct Response & $\mathrm{x}$ & 0 \\
\hline $\begin{array}{l}\text { Left } \\
\text { Right }\end{array}$ & $\begin{array}{l}.45^{*} \\
.05 \dagger\end{array}$ & $\begin{array}{l}.05 \dagger \\
.45^{*}\end{array}$ \\
\hline
\end{tabular}

Note-Probabilities for sample subject for whom flanker $X$ cues left response and flanker $O$ cues right response. ${ }^{*}$ Conditions with valid correlational cue. + Conditions with invalid correlational cue. relevant (Logan \& Zbrodoff, 1979; Ostry, Moray, \& Marks, 1976). If task relevance and priming are not crucial to the identification of unattended stimuli as assumed by late-selection models, similar effects should be found for unattended, unprimed stimuli.

\section{EXPERIMENT 1}

The first experiment simply tested for the correlational cuing effect. Two levels of correlational cue validity $(92 \%$ vs. $58 \%$ ) were used to see whether the strength of the correlation would influence the cuing effect if it was indeed present.

\section{Method}

Subjects. Twenty-four right-handed undergraduates at the University of California, San Diego, served as subjects in partial fulfillment of a course requirement. Each subject was tested in a single session lasting about $45 \mathrm{~min}$.

Apparatus and Stimuli. Stimuli were presented and responses and their latencies recorded by a Terak 8510a microcomputer. Stimulus displays were viewed from a distance of about $60 \mathrm{~cm}$. Stimuli were capital letters about $1.2^{\circ}$ wide and $1.5^{\circ} \mathrm{high}$, and adjacent letters were separated by about $0.3^{\circ}$. Subjects made their responses by pressing one of two keys on the computer keyboard with the left or right index finger.

Procedure. Each subject served in two blocks of 192 trials. For each subject, 12 letters were selected randomly (without replacement) from the letters A-W, and 6 of these were used in each block: 2 were targets assigned to the left response, 2 were targets assigned to the right response, and 2 were used as flankers. In the highcorrelation block, one flanker was presented on 88 trials with a target assigned to the left-hand response and on only 8 trials with a target assigned to the right-hand response. Complementary frequencies were used for the other flanker, so the two flankers were used equally often overall. In the low-correlation block, the flanker frequencies were 56 and 40 instead of 88 and 8 . The order of the two blocks was counterbalanced across subjects.

The subjects were told that they would be presented with three letters in a row, and that they were to respond to the middle letter and ignore the two on the outside. They were told to respond as quickly as possible without making too many errors. At the beginning of each block, the subjects were given the two target letters assigned to each response for that block.

Each trial began with the presentation of the three-letter stimulus display, consisting of a center target letter and two identical flanker lefters. This display remained on the screen until the subject responded or a 10-sec deadline had passed, at which time accuracy feedback was presented for $1 \mathrm{sec}$. The next stimulus display appeared about $1.5 \mathrm{sec}$ after the offset of the feedback for the previous trial. No warning signal or fixation point was used. Any trial on which the response took longer than $2 \mathrm{sec}$ was discarded and rerun later in the block.

\section{Results and Discussion}

Mean RTs and percentages of correct response (PCs) were computed separately for each combination of subject, block, response, and validity of correlational cue. Figure 1 shows RT as a function of block and validity, averaging across the other two factors of the design. As is evident in the figure, correlational cuing can affect RT. Responses were $60 \mathrm{msec}$ faster for valid than for invalid correlational cues in the high-correlation block $[F(1,22)$ 


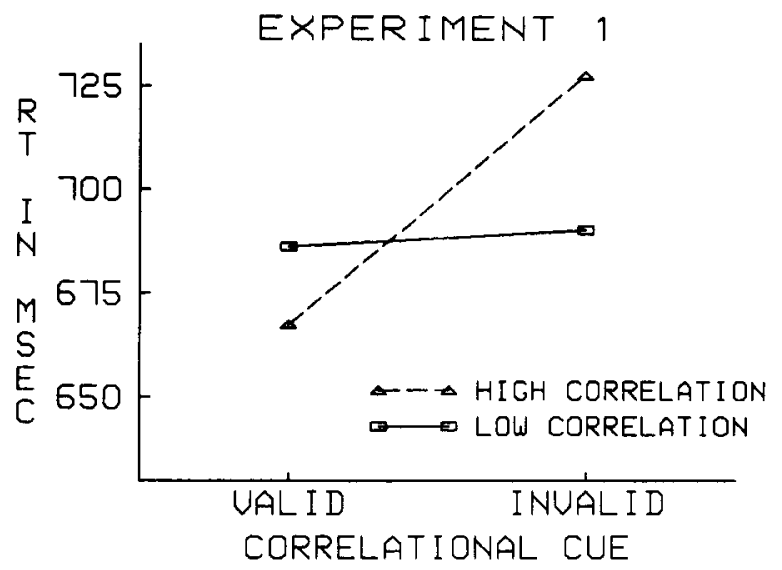

Figure 1. RT as a function of cue validity and block in Experiment 1 .

$=10.4, p<.01, M S e=16,708]$. In the low-correlation block, however, responses were only $4 \mathrm{msec}$ faster for valid than for invalid cues $[F(1,22)=0.35, p>.10$, $M S e=2,191]$. In an analysis including both blocks, the interaction of block and cuing was significant $[F(1,22)$ $=7.0, p<.02, \mathrm{MSe}=10,828]$.

The analysis of PCs provided no evidence that any of the effects were due to speed-accuracy tradeoffs. Accuracies were $97 \%-99 \%$ for all of the conditions shown in Figure 1, and longer latencies were generally associated with lower accuracies. In an overall analysis of the PCs, the only significant source of variance was the interaction of cue validity with response hand $[F(1,22)=7.0$, $p<.02, M S e=15.1]$, reflecting slightly more accurate responses with valid than with invalid cues for the right hand but a slight reversal for the left hand. There is no obvious explanation for this interaction, and it was not replicated in any of the subsequent extensions of the experiment.

The correlational cuing effect obtained in the highcorrelation block shows that letters irrelevant in both position and identity can affect RT. In particular, it demonstrates that associative learning can connect unattended flankers with correct responses. This, in turn, suggests that unattended letters are sometimes identified even when they are not primed, and, to that extent, the results provide evidence against the attenuation-and-priming account of selective-attention failures. However, before the attenuation-and-priming model can be completely ruled out, it must be established that the correlational cuing effect actually results from semantic processing of the unattended flankers rather than from associative learning based on some nonsemantic processing.

For example, one simple alternative explanation of the correlational cuing effect, consistent with the attenuationand-priming model, is that the operative variable is the correlation of the response with a visual feature of the flanker rather than its identity. There is some evidence that visual features of targets can activate responses directly (Dykes \& Pascal, 1981; C. W. Eriksen \& Schultz, 1979; Yeh \& C. W. Eriksen, 1984; but see Miller, 1979), so it is possible that the visual features of these response-correlated flankers also do so. If a visual feature-response correlation is responsible for the effect, of course, then the effect indicates only that unattended flankers receive featural analysis by the visual system. Since feature processing takes place before identification (Neisser, 1967), this explanation of the cuing effect is compatible with the attenuation-and-priming model, which assumes only that unattended and unprimed letters are not processed to the point of identification.

To help rule out this alternative explanation of the results, 18 more subjects were run in a modified version of the experiment. An additional 24 trials were mixed into each block, and on these trials flankers were letters that were visually similar to one of the response-correlated flankers that appeared on the regular trials (cf. Miller \& Bauer, 1981). For example, the flanker letter $E$ might be correlated with a response on the regular trials and the letter $\mathrm{F}$ might be used as a flanker on some of the additional trials. The similar flankers were included to see whether the cuing effect would transfer from the responsecorrelated flankers to other letters sharing the same visual features. In the high-correlation block, the cue validity effect was $48 \mathrm{msec}[F(1,16)=6.8, p<.02, M S e=$ $5,940]$, but the analogous effect was not obtained with the visually similar flankers (an average effect of $1 \mathrm{msec}$ in the wrong direction). Since letters with similar visual features did not produce the cuing effect, it appears that the correlational cuing effect depends on the identities, not the visual features, of the response-correlated flankers.

Since there was no cuing effect in the low-correlation condition, it is reasonable to consider this a neutral condition for the purpose of establishing the relative facilitation and inhibition effects of valid and invalid cues in the high-correlation condition. In these data, both effects were present, with the absolute magnitude of facilitation being about half that of inhibition.

\section{EXPERIMENT 2}

Though the results of Experiment 1 demonstrate that identities of unprimed flankers can influence responses, the dependence of this effect on semantic processing of flankers needs further support. The possibility most inconsistent with the attenuation-and-priming model is that flankers are identified by the semantic system, that the association between flanker identity and correct response is learned across a series of trials, and that flanker identities come to activate responses directly by virtue of that association (Mackintosh, 1983). According to this model, once the association has been established, a correlated flanker will activate a response in just the same way as a target in the flanker position would (Coles et al., 1985).

Another possibility, much more consistent with the attenuation-and-priming model, is that the correlational cuing effect is simply one of display probability. By defi- 
nition, stimulus displays with valid correlational cues are presented much more often than displays with invalid cues. Since there is reason to believe that perceptual processing may be faster for displays of higher probability (e.g., Estes, 1982; Miller \& Pachella, 1973), it is possible that the correlational cuing effect results from the relative speeds of perceptual processing for displays with valid and invalid cues. Even if this advantage for highprobability displays were dependent on the complete physical form of the flanker, rather than being associated with a particular feature, it would not show semantic processing of the unattended flankers in any interesting sense.

Experiments 2 and 3 were designed to compare the response-activation and display-frequency explanations of the cuing effect. The logic of Experiment 2 was to see whether the correlational cuing effect was specific to the exact stimulus displays used to induce it, as predicted by the display-frequency explanation, or if it generalized to different displays with the same flankers, as predicted by the response-activation explanation. The design was very similar to that of Experiment 1, except that a third target letter was assigned to each response.

Table 2 summarizes the display presentation frequencies. For two of the target letters assigned to each response, one flanker was much more common than the other flanker. These inducing targets were comparable to those used in Experiment 1, because they were used to establish a correlation between flanker identity and correct response. The third target letter assigned to each response-the test target-appeared equally often with each flanker letter. The display-frequency and responseactivation explanations of the cuing effect make different predictions about what effect should be observed for the test target.

If display-frequency imbalance is responsible for the cuing effect, cue validity should have a large effect for the inducing targets but no effect for the test target. For the inducing targets, the probabilities of valid and invalid displays are even more uneven than they were in Experiment 1 , so the perceptual effects of display frequency should again be large. For the test target, however, probabilities of valid and invalid displays are equal, so type of cuing should have no effect.

Table 2

Number of Trials for Each Target-Flanker Combination in Experiment 2

\begin{tabular}{|c|c|c|c|c|}
\hline \multirow{2}{*}{$\begin{array}{l}\text { Target } \\
\text { Letter }\end{array}$} & \multirow{2}{*}{$\begin{array}{c}\text { Correct } \\
\text { Response }\end{array}$} & \multicolumn{2}{|c|}{$\begin{array}{l}\text { Number of Trials } \\
\text { With Each Flanker }\end{array}$} & \multirow[b]{2}{*}{ Target Type } \\
\hline & & $X$ & 0 & \\
\hline $\mathrm{T} 1$ & Left & $30 *$ & $2 \dagger$ & Inducing \\
\hline $\mathrm{T} 2$ & Left & $30 *$ & $2 \dagger$ & Inducing \\
\hline $\mathrm{T} 3$ & Left & $16^{*}$ & $16 t^{\dagger}$ & Test \\
\hline T4 & Right & $2 \dagger$ & $30^{*}$ & Inducing \\
\hline $\mathrm{T} 5$ & Right & $2 \dagger$ & $30 *$ & Inducing \\
\hline T6 & Right & $16 \dagger$ & $16^{*}$ & Test \\
\hline
\end{tabular}

Note-Number of trials for sample subject for whom flanker $\mathrm{X}$ cues left response and flanker $O$ cues right response. ${ }^{*}$ Conditions with valid correlational cue. +Conditions with invalid correlational cue.
If response activation causes the cuing effect, the effect should be equally large for inducing and test targets. According to this explanation, the operative variable is the overall correlation between flanker identity and correct response, and this correlation does not depend on the identity of the target. Thus, flankers should activate responses equally strongly for inducing and test targets. This explanation also predicts that the cuing effect should be much smaller in this experiment than in Experiment 1, because the overall correlation between flanker identity and response is much weaker in this experiment. The many invalid cue trials with test targets reduce overall cue validity to only $79 \%$ in the second experiment, as compared with $92 \%$ in the high-correlation block of the first.

Of course, both display probabilities and response activation may contribute to correlational cuing. If so, there should be a cuing effect for the test target because of response activation, but there should be a larger cuing effect for the inducing targets because of the additional contribution of display probability.

\section{Method}

The apparatus and stimuli were the same as those used in the previous experiment. The differences in procedure were as follows: Each subject was run in two blocks of 192 trials, with three randomly selected targets assigned to each of the two responses and two randomly selected flanker letters. Only the random ordering of stimulus displays was changed between blocks. The frequencies of the different target/flanker combinations are shown in Table 2 . There were 46 new subjects drawn from the same pool.

\section{Results and Discussion}

Figure 2 shows the obtained average RTs as a function of cue validity for both inducing and test targets. For inducing targets, responses were $19 \mathrm{msec}$ faster for valid than for invalid correlational cues; for test targets, the effect was 12 msec. Overall, the effect of correlational cue validity was significant $[F(1,45)=8.1, p<.01, M S e$ $=5,547]$, but the interaction of cue validity with target type (inducing vs. test) was not $[F(1,45)=0.48, p>$ $.20, M S e=4,208]$. The effect of cue validity was also significant in a separate analysis that included only the test target $[F(1,45)=4.28, p<.05, M S e=3,247]$. In an analysis of PCs, the only significant effect was that of cue validity $[F(1,45)=4.72, p<.05, M S e=15.6]$, with responses being more accurate on trials with valid as opposed to invalid cues $(98.5 \%$ vs. $97.9 \%)$.

Three other sources of variance were also significant in the overall analysis of RT. First, there was a practice effect, manifested in a 54-msec advantage of responses in the second block over those in the first $[F(1,45)=20$, $p<.01, M S e=26,921]$. Second, as is apparent in Figure 2, there was a 23-msec advantage in responding to inducing targets over responding to test targets $[F(1,45)$ $=10.6, p<.01, M S e=9,454]$. Third, the advantage for inducing targets was almost entirely for left- rather than right-hand responses ( $40 \mathrm{vs.} 6 \mathrm{msec}$ ), resulting in a significant interaction of target type and response hand 


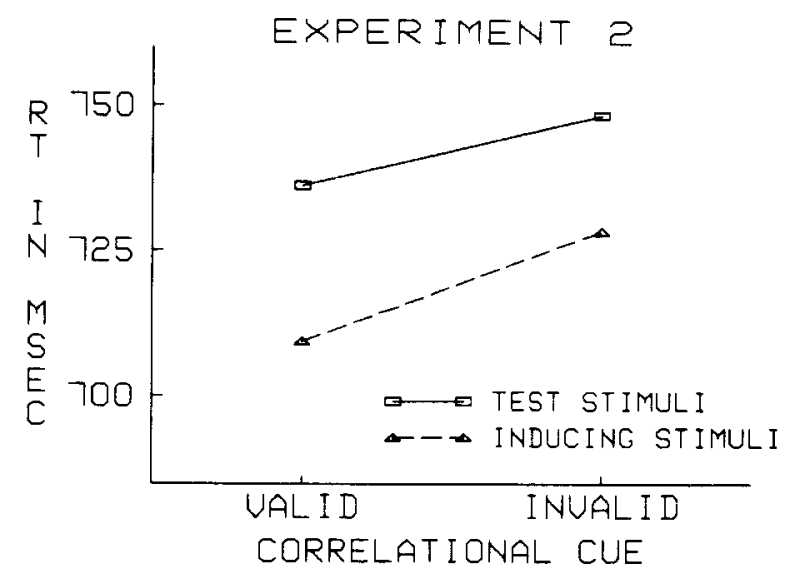

Figure 2. RT as a function of cue validity for inducing and test stimuli in Experiment 2.

$[F(1,45)=4.95, p<.05, M S e=10,668]$. The effect of target type and its interaction with response hand are probably artifacts of the instructions. At the beginning of the experiment, the three target letters for each response were displayed on the screen from left to right, with the test target in the rightmost position for every subject. Assuming that subjects read the targets from left to right, and rehearsed the targets in the order in which they read them, the effect of target type could be due to less rehearsal of the test target (cf. Seamon \& Wright, 1976). That the effect was observed primarily for left-hand responses is also consistent with the rehearsal explanation. Subjects may rehearse one set of targets and make the other response by default when none of these targets is present (cf. Biederman \& Stacy, 1974), and the set of targets for the left-hand response might have been rehearsed more often because of input primacy.

The effects of correlational cuing observed in this experiment suggest that the cue operates primarily or solely by activating responses, because all three predictions of the response-activation explanation were confirmed. The cuing effect was much smaller in this experiment than in Experiment 1, the effect was significant for test stimuli as well as inducing stimuli, and the effect was not significantly larger for inducing targets than for test targets. These findings contradict the hypothesis that display probability is the operative variable. Because the correlation of flanker identity with response is more important than the correlation of flanker identity with target identity, the cuing effect probably does not arise within perceptual processes. Thus, this experiment supports the hypothesis that the cuing effect results from semantic processing of the flankers, and provides evidence against the attenuation-and-priming model.

\section{EXPERIMENT 3}

The results of Experiment 2 suggest that when a flanker is correlated with a response, the flanker acquires a general power to activate that response. Experiment 3 sought to provide further evidence of this power to activate responses by showing that it could transfer to a somewhat different experimental context.

For the first two blocks of trials-the inducing blockssubjects performed a selective-attention task with response-correlated flankers, as in the previous experiments. In a third test block, however, the subjects were asked to respond to different center target letters. Specifically, the letters that had been used as the responsecorrelated flankers in the inducing blocks became the targets for the test block, and new flankers were used for this block. When it became a target letter in the test block, each of the previously response-correlated flankers could be assigned to the same response with which it had been correlated in the inducing blocks (compatible) or it could be assigned to the opposite response (incompatible).

If response-correlated flankers acquire a generalized power to elicit the associated response, then test-block responses should be faster for compatibly assigned targets than for incompatibly assigned ones. For compatibly assigned targets, correct responses would be activated both by this generalized power and by the intentional processes that carry out the selective-attention task. Especially fast responses would result from the combination of these two sources of activation (Miller, 1982). For incompatibly assigned targets, however, the two sources of activation would compete, and the generalized activation process would partially inhibit the response that received activation from intentional processes, resulting in slower responses. If, however, the correlational cuing effect results from something other than activation of responses by correlated flankers (or if the acquired power to activate a response is specific to the inducing task), then test-block responses to compatibly and incompatibly assigned targets should be equally fast.

\section{Method}

This experiment was conducted using the same apparatus and stimuli used previously. Each of the two inducing blocks was 80 trials long. For these blocks there were two target letters assigned to each response, and four flanker letters were used-two associated with each response. Two of the flanker letters appeared nine times with each of the targets assigned to the left-hand response and only once with each of the targets assigned to the right-hand response. The other two flankers appeared with complementary frequencies.

The test block was also 80 trials long. Of the two flankers previously associated with the left-hand response, one was assigned as a target for the left-hand response (compatible) and one was assigned as a target for the right-hand response (incompatible). The two flankers previously associated with the right-hand response were divided up in the same way. Four new letters were used as flankers for this block. Each of the four targets was tested five times with each of the four new flankers. There were 27 new subjects drawn from the same pool.

\section{Results and Discussion}

As in the previous experiments, a 35-msec effect of correlational cue validity was observed in the inducing blocks $[F(1,26)=6.9, p<.02, M S \mathrm{e}=9,337]$. This effect is 
somewhat smaller than the one observed in the highcorrelation block of the first experiment, possibly because cue validity was not quite as high $(90 \%$ vs. $92 \%)$. Another important factor may have been that the blocks were shorter in this experiment, and the correlational cuing effect necessarily takes some time to build up. Here, the cue validity effect was $13 \mathrm{msec}$ in the first block and $55 \mathrm{msec}$ in the second.

The interesting finding of this experiment is that there was a significant compatibility effect in the test block $[F(1,27)=6.5, p<.02, M S e=2,643]$. That is, testblock responses were faster to compatibly assigned targets $(641 \mathrm{msec})$ than to incompatibly assigned targets (666 msec). Responses were also more accurate to compatible $(98.1 \%)$ than to incompatible $(97.0 \%)$ targets, although this effect was not significant $[F(1,27)=2.4$, $p<.15, M S \mathrm{e}=11.66]$.

The compatibility effect observed in this experiment is further evidence that the correlational cuing effect is caused by response activation established from the correlation of a particular flanker with a particular response. This compatibility effect cannot have been mediated by display probability, flanker-target associations, or any strategy involved in blocks in which the correlation is present, since none of these factors was present in the test block of this experiment.

It is evident that the correlation of an identity with a response establishes a general tendency for that identity to elicit the response, since this tendency carried over to a new situation in which the identity was relevant to the task. In the case of incompatibly assigned targets, response activation must have occurred even though it was contrary to the subject's intentions. Because the response activation produced by flankers carries over to a task in which the flankers themselves become targets, it seems very likely that this activation depends on semantic processing of the flankers.

\section{EXPERIMENT 4}

Experiments 1-3 established the correlational cuing effect and provided evidence that it resulted from semantic processing of flankers. Thus, these experiments challenge the attenuation-and-priming model by showing what appears to be an identity effect of unattended, unprimed letters. But are they really unattended?

Experiments 4 and 5 investigated the extent to which the subjects are aware of the correlation between flanker identities and correct responses. Although the effect of this correlation on RT is problematic for the attenuationand-priming model, it can be reconciled with the model by assuming that subjects consciously notice the correlation between flanker identities and correct responses, and thereafter attend to the flankers.

To reconcile the correlational cuing effect with the attenuation-and-priming model, first consider how subjects might become aware of the correlation between flanker identity and correct response. At the start of the experiment, flankers would be unattended and unprimed, so they would not be identified in the interval between stimulus presentation and response. However, subjects might shift attention to the flankers after responding to each target, and would probably still have adequate iconic information for flanker identification at that point (Sperling, 1967). The task is certainly not demanding enough to require concentration in the intertrial interval, and subjects might shift attention to the flankers from simple boredom or in an attempt to figure out the purpose of the experiment. It is not obvious that subjects would spontaneously adopt this effortful (cf. Posner, Cohen, Choate, Hockey, \& Maylor, 1984), attention-switching, and problem-solving secondary task instead of letting their thoughts wander to personal concerns, but it is possible. Thus, even if the attenuation-and-priming model correctly describes processing during the trial, it is possible that subjects learn flanker-response correlations based on attended flanker identifications that take place retrospectively (i.e., after response selection on each trial).

After subjects have learned about the correlation between flanker identity and the correct response, the attenuation-and-priming model could explain the influence of this correlation on RT in either of two ways. First, the subjects might allocate extra attention to the flankers, since the flankers provide a fairly reliable redundant cue to the correct response. Obviously, attended processing of the flankers could produce the correlational cuing effect without invalidating the attenuation-and-priming model. Second, even if the subjects did not allocate attention to the flankers, the identities of response-correlated flankers might become primed once the subjects became aware of their informational value (task-relevance). Once primed, of course, even unattended flankers would be identified, according to the model, so they could produce the cuing effect.

Although these explanations are somewhat ad hoc, it is clear that one can reconcile the attenuation-and-priming model with the correlational cuing effect by assuming that retrospective flanker identifications allow subjects to notice the correlations of flanker identities with correct responses. Experiment 4 was therefore designed to test whether subjects did, in fact, notice these correlations. The subjects were simply asked, at the end of the experiment, whether they had noticed any association of flanker identity and response.

This experiment also tested three predictions derivable from the hypothesis that subjects pay extra attention to the flankers once they notice the correlation between flankers and correct responses. To this end, three groups of subjects were run, with different numbers of correlated flankers for subjects in different groups, ${ }^{4}$ as shown in Table 3. Each subject saw six randomly selected flanker letters. For subjects in the "fully correlated" group, three flankers were correlated with each response. For subjects in the "partially correlated" group, one flanker was correlated with each response and the other four flankers were not response-correlated. For subjects in the "uncor- 
Table 3

Flanker Cuing Status by Group in Experiment 4

\begin{tabular}{clll}
\hline Flanker & $\begin{array}{c}\text { Fully } \\
\text { Correlated } \\
\text { Group }\end{array}$ & $\begin{array}{c}\text { Partially } \\
\text { Correlated } \\
\text { Group }\end{array}$ & $\begin{array}{c}\text { Uncorrelated } \\
\text { Group }\end{array}$ \\
\hline 1 & Left & Left & Uncorrelated \\
2 & Left & Uncorrelated & Uncorrelated \\
3 & Left & Uncorrelated & Uncorrelated \\
4 & Right & Right & Uncorrelated \\
5 & Right & Uncorrelated & Uncorrelated \\
6 & Right & Uncorrelated & Uncorrelated \\
\hline
\end{tabular}

related" group, none of the six flankers was correlated with a response.

If it is true that subjects pay extra attention to the flankers because of the correlations of flanker identities and correct responses, then the three groups should differ in the amount of attention they pay to the flankers. Subjects in the fully correlated group should pay the most attention to the flankers, since the flankers are most correlated (on average across flankers) for these subjects. Subjects in the uncorrelated group should pay minimal attention to the flankers, since these flankers are completely uncorrelated with responses. Subjects in the partially correlated group should pay an intermediate amount of attention to the flankers, since their flankers are (on average) partially, but not strongly, predictive of responses.

To evaluate the hypothesis that the presence of correlated flankers induces subjects to pay extra attention to the flankers, this experiment included three indices of the amount of attention paid to flankers. First, subjects were asked to recall as many flankers as they could at the end of the experiment. If subjects in the fully correlated group pay most attention to the flankers, then they should be able to name the most flankers in this recall test. Second, the Eriksen effect was evaluated for each subject, using occasional trials on which target letters (compatible or incompatible) appeared in flanker positions. If subjects in the fully correlated group pay most attention to the flankers, then they should also be most influenced by the response compatibility of these flankers. Third, the correlational cuing effect itself was compared across the fully and partially correlated groups. If subjects in the fully correlated group pay more attention to the flankers than subjects in the partially correlated group, then the correlational cuing effect should be larger for subjects in the former group.

\section{Method}

This experiment was controlled by an Apple II+ microcomputer. Stimuli were uppercase consonants in the standard computer font, measuring about $0.5^{\circ}$ high and $0.3^{\circ}$ wide, with a center-to-center distance of about $1^{\circ}$ between the target and each adjacent flanker. Responses were made by pressing keys on the standard computer keyboard. The trial structure differed from that of the previous experiments only in that a plus sign, serving as a fixation point and warning signal, was presented for $500 \mathrm{msec}$ ending $1 \mathrm{sec}$ before stimulus onset.
Twenty-five subjects were tested in each of the three groups shown in Table 3. For each subject, each of two randomly selected target letters was assigned to each of the two responses, and six other letters were randomly selected for use as flankers. Each subject was tested in three blocks of trials, with 20 warm-up trials preceding the experimental trials of the first block and 4 warm-up trials at the beginning of the second and third blocks. Each block included the same 168 experimental trials, with a different random order generated for each block.

Within each block, each target letter was presented in the relevant center position of the display 42 times. A given target letter was presented 9 times with each flanker correlated with the response that was correct for that target, once with each flanker correlated with the response that was incorrect for that target, and 5 times with each flanker that was response uncorrelated, for a total of $\mathbf{3 0}$ presentations across the six flankers for each subject in all three groups. For the other 12 presentations of each target, the flankers were also one of the targets (these trials were included to evaluate the Eriksen effect). Of these 12 presentations, 3 were with each of the four target letters appearing in the flanker positions.

At the end of the experiment, the experimenter immediately entered the experimental chamber and asked the subject to name all of the letters that had appeared "in the left and right positions of the rows of letters." Then the subject was asked: "Did you notice that any of these outside letters were associated with either of the two responses in particular? In other words, when certain outside letters appeared the response was almost always the same. Do you know which outside letters these were and which response went with each one?"

\section{Results and Discussion}

The correlational cuing effect was smaller in this experiment than in previous ones, averaging $20 \mathrm{msec}$ for subjects in the fully and partially correlated groups, but the small effect was highly reliable $[F(1,48)=6.19$, $p<.02, M S e=9,567]$. It seems likely that the decrease in effect size results from the reduced number of presentations of each particular correlated flanker letter, since there is less opportunity to learn the correlation with fewer presentations.

In response to the question asking them to identify response-correlated flankers, subjects clearly guessed. Of the 25 subjects in each group, 1 subject from the fully correlated group and 1 subject from the partially correlated group each named one of the response-correlated flankers and correctly indicated which response it was correlated with. Five other response-correlated letters were named by subjects in these groups, but the subjects said that they had been correlated with one response when, in fact, they had been correlated with the opposite response. Across all three groups, 33 letters that had never appeared as flankers in the experiment were named in response to this question $(9,11$, and 13 from the fully correlated, partially correlated, and uncorrelated groups, respectively). Given such results, it is clear that subjects are not aware of the flanker-response correlation that produces the correlational cuing effect.

Three aspects of the results also contradict the hypothesis that subjects pay extra attention to the flankers because of the correlational cuing manipulation. First, in response to the request to name as many flankers as possible, the 
Table 4

RT (in Milliseconds) as a Function of Flanker

Compatibility in Experiment 4

\begin{tabular}{lccc}
$\begin{array}{c}\text { Relationship } \\
\text { of Flanker } \\
\text { to Target }\end{array}$ & $\begin{array}{c}\text { Fully } \\
\text { Correlated } \\
\text { Group }\end{array}$ & $\begin{array}{c}\text { Partially } \\
\text { Correlated } \\
\text { Group }\end{array}$ & $\begin{array}{c}\text { Uncorrelated } \\
\text { Group }\end{array}$ \\
\hline Identical & 763 & 712 & 718 \\
Response-Compatible & 751 & 714 & 716 \\
Response-Incompatible & 810 & 749 & 747 \\
\hline
\end{tabular}

three groups were able to recall about the same proportions of flankers [fully correlated group $=16 \%$, partially correlated group $=21 \%$, uncorrelated group $=15 \%$; $F(2,72)=0.95, p>0.3$ ]. Subjects in the partially correlated group were slightly less likely to recall flankers that had been correlated $(14 \%)$ than flankers that had been uncorrelated $(24 \%)$, although the difference was not statistically reliable $[F(1,24)=3.2, p>.05]$. Again, it appears that subjects were mainly guessing in response to this question as well: They correctly named an average of one flanker each, but in addition named an average of 1.63 letters that had not appeared as flankers in the experiment.

Second, as shown in Table 4, the Eriksen effect also did not differ significantly among groups, as it should have if response correlations caused subjects to pay extra attention to the flankers $[F(4,144)=1.48, p>.20]$.

Third, the size of the correlational cuing effect itself did not differ significantly between the two groups that had correlated flankers $[F(1,48)=.165, p>.6]$, as it should have if subjects in the fully correlated group had paid more attention to the flankers than had subjects in the partially correlated group. There was a significant three-way interaction of group, block, and cuing $[F(2,96)$ $=4.39, p<.02, M S \mathrm{e}=5,890]$ reflecting the fact that the correlational cuing effect was entirely in the third block for the partially correlated group but was spread evenly across blocks for the fully correlated group.

In summary, the results of this experiment provide no support for the hypothesis that the correlational cuing manipulation is produced by an awareness of the correlation between flanker identities and responses, coupled either with attention to the flankers or with priming of response-correlated flanker identities. Thus, this experiment provides evidence that the correlational cuing effect actually results from identification of unattended and unprimed letters, contrary to the attenuation-and-priming model.

It is somewhat surprising that subjects were able to recall so little about the flankers in this experiment. From previous discussions of the late-selection implications of the Eriksen effect (e.g., Van der Heijden, 1981), one would assume that the full semantic processing that produces the response-compatibility effect on RT would also result in significant memory for the flankers. Apparently, this is not the case. Thus, this experiment demonstrates not only another instance in which learning can occur without awareness of contingency (cf. Silver,
Saltz, \& Modigliana, 1970), but also an instance in which learning can occur with little awareness of the identities of the very items involved in the contingency.

\section{EXPERIMENT 5}

The most striking result of Experiment 4 was that subjects showed virtually no awareness of the correlation between flanker identities and correct responses, at least as indicated by their inability to report flanker letters that are associated with responses. The purpose of this experiment was to test for such awareness by using a much more lenient criterion. Subjects were not directly asked whether they noticed any correlations, but instead were asked to estimate the frequencies with which the various stimulus displays (flanker-target-flanker) had been presented. Subjects can accurately estimate stimulus frequencies, even when they do not know that they will be asked to do so and perhaps even when they pay little attention to the stimuli whose frequencies will be estimated (Hasher \& Zacks, 1979, 1984), although paying attention does seem to improve frequency estimates (e.g., Greene, 1984). On the other hand, subjects are not so good at estimating correlations, except perhaps with continuous variables (Alloy \& Tabachnik, 1984). To provide the most sensitive measure of whether subjects noticed the correlation, then, frequency estimates for the stimulus displays were collected. If a subject's frequency estimates showed a disparity in the correct direction (higher frequency estimates for trials with valid flankers than for ones with invalid flankers), then it was assumed that the subject had noticed the correlation.

Another methodological aspect of this experiment warrants special discussion. The cue validity was $83 \%$-lower than in the previous experiments. A low validity was used to reduce the probability that the subjects would notice the correlation of flanker identity with response. Obviously, if subjects always noticed the correlation, it would be impossible to tell whether the cuing effect would be obtained even when they did not notice it.

\section{Method}

The apparatus, stimuli, and trial structure for this experiment were the same as those in Experiment 4.

Twenty-four subjects were tested in three blocks of 192 trials, with blocks varying only in the random sequence of stimulus displays. Each of two randomly selected target letters was assigned to each of the two responses, and two other letters were randomly selected for use as flankers. Each target letter was presented $\mathbf{4 0}$ times with the flanker correlated with its correct response, and 8 times with the flanker associated with the other response, producing an overall cue validity of $83 \%$.

At the end of the experiment, subjects were given a questionnaire listing the eight stimulus displays they had seen (4 targets $x$ 2 flankers) and four displays they had not seen (4 targets with a new flanker). They were asked to indicate the percentage of times that they had seen each of the displays in the experiment, and they were allowed as much time as they needed to complete the questionnaire. The order of the displays on the questionnaire was randomized separately for each subject. 


\section{Results and Discussion}

One subject was omitted from the analysis because he indicated on the questionnaire that he had never seen any of the stimulus displays. For the other 23 subjects, a small, but statistically reliable, effect of correlational cuing was obtained, with average RTs of 664 and $686 \mathrm{msec}$ for valid and invalid cuing, respectively $[F(1,22)=10.6, p<.01$, $M S e=3,119$ ]. Responses were also slightly more accurate on trials with valid cues $(98.2 \%$ vs. $97.8 \%)$, but this difference was not significant $[F(1,22)=1.38, p>$ $.20, M S \mathrm{e}=8.37]$.

The estimates of display frequency were very accurate for the displays that had never appeared in the experiment, with an average frequency estimate of only $0.24 \%$. For the displays that had been used, however, frequency estimates were much less accurate. Subjects rated the highfrequency displays as having occurred more often than the low-frequency displays $[13.74 \%$ vs. $10.32 \% ; F(1,22)$ $=4.78, p<.05, M S e=112]$, but the frequency estimates were not nearly as discrepant as the objective frequency values $(20.83 \%$ vs. $4.17 \%)$. Thus, by this more lenient criterion, it appears that subjects were to some extent aware of the correlation between flanker identity and correct response.

To see whether awareness of the correlation was necessary for the cuing effect to occur, the two flankers were considered separately. If a subject's total frequency estimate was higher for displays in which the flanker appeared as a valid cue than for displays in which it appeared as an invalid cue, then the subject was assumed to have been aware of the correlation for that flanker. By this criterion, 3 of the 23 subjects were not aware of the correlation for either flanker and 9 subjects were not aware of the correlation for one flanker. Considering only trials with these flankers, responses were $34 \mathrm{msec}$ faster for displays with valid rather than invalid flanker cues $[t(11)$ $=2.37, p<.05]$, a cuing effect even larger than that found in the data set as a whole. Considering only the flankers for which the correlation was noticed, the cuing effect was only $11 \mathrm{msec}[t(19)=1.2, p>.2]$. Thus, it appears that conscious awareness of the correlation not only is not necessary for the cuing effect but may even inhibit it.

\section{EXPERIMENT 6}

The correlational cuing effect demonstrated in the first five experiments indicates that priming is not necessary for unattended letters to influence responses, but it does not indicate that priming is completely without effect. All of the flankers examined thus far had been unprimed, and it is possible that even larger correlational cuing effects would have been obtained with primed flankers. The purpose of Experiment 6 was to see whether priming had any influence at all on selectivity.

The goal of the experiment required a comparison of the correlational cuing effect for primed and unprimed flankers. Targets from the focused-attention task could have been used as the primed flankers, but it was feared that these letters already had such strong tendencies to activate responses (by virtue of their instructed response assignments) that their ability to produce a correlational cuing effect would be concealed. Instead, the primed flankers were target letters from a separate visual search task that was performed on alternating blocks of trials with the focused-attention task. This is a weaker priming manipulation than would be one using the targets from the focused-attention task itself, but the results suggest that it was effective.

\section{Method}

The apparatus, stimuli, and trial structure for this experiment were the same as those in Experiments 4 and 5.

Forty subjects were tested in eight blocks of trials. In four of the blocks, with 64 trials per block, a visual search task was used, and in the other four blocks, with 96 trials per block, a focusedattention task was used. The two types of blocks alternated, with each focused-attention block immediately following a visual search block. Separate target letters were selected randomly for the two tasks, and within each task, the target letters remained the same throughout the experiment.

Search task. Each subject had two randomly selected target letters. The subjects were instructed to respond by pressing a key with the right middle finger if either of these letters was present anywhere in the display and to respond by pressing a key with the left middle finger if neither was present. Each display had four letters presented at the four corners of an imaginary square, with a distance of about $1^{\circ}$ from the fixation point to each corner. Half of the displays had one target and three distractors; the other half had four distractors. Neither targets nor correlated flankers from the focused-attention task ever appeared as distractors in the visual search task.

Focused-attention task. The three letters in each stimulus row were separated by only about $0.1^{\circ}$ to maximize the processing of flankers, thus providing the most sensitive comparison of primed and unprimed flankers. Two target letters were assigned to each of two responses, made with the left and right index fingers. Two letters were randomly selected to be the unprimed flankers, and one of these was correlated with each response. The targets from the visual search task served as primed flankers, with a random assignment of these two targets to their associated responses. Each of the focused-attention targets was presented 11 times per block with each of the two flankers (primed, unprimed) correlated with its correct response and only once with each of the flankers associated with the opposite response, producing an overall cue validity of $92 \%$.

\section{Results and Discussion}

Table 5 shows average RT and PC as a function of correlational cuing and priming for the focused-attention task. As in previous experiments, there was a significant overall

Table 5

RT (in Milliseconds) (PC) as a Function of Priming and Correlational Cuing in Experiment 6

\begin{tabular}{lccc}
\hline & \multicolumn{2}{c}{ Correlational Cue } & \\
\cline { 2 - 3 } Flanker Type & Valid & Invalid & Average \\
\hline Primed & $770(97.0)$ & $804(95.6)$ & $787(96.3)$ \\
Unprimed & $766(96.6)$ & $802(93.1)$ & $784(95.0)$ \\
Average & $768(96.9)$ & $803(94.4)$ & \\
\hline
\end{tabular}


effect of correlational cuing on both $\mathrm{RT}[F(1,39)=22$, $p<.01, M S e=16,830]$ and $\mathrm{PC}[F(1,39)=19, p<$ $.01, M S e=103]$. Priming did not significantly affect response latency $[F(1,39)<1]$, but it did increase response accuracy $[F(1,39)=8.5, p<.01, M S e=70]$. The effect of correlational cuing on RT was approximately the same with primed (34 msec) and unprimed (36 msec) flankers $[F(1,39)<1]$, but correlational cuing had a reliably larger effect on PC with unprimed flankers $(3.7 \%)$ than with primed flankers $(1.4 \%)[F(1,39)=6.5, p<$ $.02, M S e=64]$.

In the analysis of RT, the only other significant sources of variance were response type $[F(1,39)=4.073, p<$ $.05, M S e=54,970]$, with right-hand responses $27 \mathrm{msec}$ faster than left-hand responses, and block $[F(3,117)=$ $5.73, p<.01, M S e=30,749$ ], with a monotonic improvement totaling $56 \mathrm{msec}$ across the four blocks of practice. In the analysis of PC, no other sources of variance were significant.

Performance in the search task was not unusual for such a task, with responses averaging $937 \mathrm{msec}$ in latency and $94.6 \%$ correct. Overall, RT decreased $85 \mathrm{msec}$ across the four blocks of practice $[F(3,117)=8.9, p<.01, M S e$ $=11,792]$, and responses were $180 \mathrm{msec}$ faster on targetpresent trials than on target-absent trials $[F(1,39)=116$, $p<.01, M S e=22,222]$. Responses were $4.2 \%$ less accurate on target-present trials $[F(3,117)=57, p<.01$, $M S \mathrm{e}=25]$, although this effect decreased across blocks $[F(3,117)=3.54, p<.02, M S e=13]$. In an analysis that included only target-present trials, target location was found to have an effect on both RT $[F(3,117)=15$, $p<.01, M S e=11,354]$ and $\mathrm{PC}[F(3,117)=5.97, p<$ $.01, M S e=125]$. Responses were both faster and more accurate when the target appeared in a location on the same side of the display as the target-present response button (i.e., right side) than when the target appeared in a location on the opposite side of the display (cf. Simon, Acosta, Mewaldt, \& Speidel, 1976).

The results of this experiment provide strong evidence against the attenuation-and-priming model. Priming of distractors certainly did not make them more difficult to ignore. In fact, since the correlational cuing effect on PC was larger for unprimed than for primed flankers, it appears that primed distractors were actually easier to ignore than unprimed ones. The reliability of this effect also provides reassurance that the priming manipulation was effective, so that the experiment was a fair test of the model.

\section{GENERAL DISCUSSION}

\section{Identity Effects of Unattended Stimuli}

The correlational cuing effect demonstrated in these six experiments contradicts the attenuation-and-priming model of selective attention, according to which unattended stimuli are recognized only if they have been primed. When unprimed flanker letters are correlated with a particular response, their identities acquire the capac- ity to activate that response, although other visually similar letters do not (Experiment 1). By virtue of this capacity, these flankers influence responses not only to target letters with which they are frequently paired, but also to target letters with which they are paired no more often than chance would dictate (Experiment 2). The capacity of response-correlated flankers to activate responses also carries over to a new task in which these letters become targets (Experiment 3). These findings suggest that the effects of response-correlated flankers are based on semantic processing, implying that these flankers have, in fact, been recognized.

The question of whether the flankers were completely unattended is difficult to settle definitively (see Kellogg, 1980), but the evidence suggests that they were. Subjects reported no awareness of the correlation between flanker identity and responses and very little awareness of the identities of the flankers (Experiments 4 and 5), suggesting that the flankers were indeed unattended. Of course, one could always try to salvage some version of an earlyselection theory by arguing that the tests for attention to flankers were insensitive (e.g., the inability to report flankers and flanker-response correlations in a postexperiment debriefing could be attributed to forgetting). Such a theoretical move, however, seems strained in the absence of positive evidence for attention to the flankers. Clearly, there is no way to falsify an early-selection theory in which any effect of a stimulus is taken as evidence that the stimulus received some attention. In any case, the inability to report flanker-response correlations seems decisive evidence against any version of the attenuationand-priming model in which subjects prime the flankers after noticing their correlation with responses.

These results extend the evidence that unattended letters are processed to the point of identification in the selective attention paradigm developed by $\mathrm{C}$. W. Eriksen and his colleagues (e.g., C. W. Eriksen \& Schultz, 1979). Previous studies have only shown that target letters appearing in irrelevant locations can activate responses in spite of the fact that they are unattended. In those studies, of course, the unattended letters were task relevant in identity, even though they were irrelevant by virtue of their position. The present studies extend these findings by showing effects of letters that are irrelevant in both identity and location.

Although the correlational cuing effect suggests that priming is not necessary for identification of unattended stimuli, it does not contradict the central assumption of early selection models: that unattended stimuli are attenuated early in processing. The attenuation assumption is logically distinct from the priming assumption, so the former may be correct even if the latter is not. As earlyselection theorists have pointed out (e.g., Egeth, 1977; Johnston \& Dark, 1982; Kahneman \& Treisman, 1984), identity effects of unattended stimuli-such as the Eriksen effect and the correlational cuing effect-indicate only that these stimuli receive some perceptual processing, not that they receive the same full processing as attended stimuli. 
Therefore, the present studies can only be regarded as evidence against two particular early-selection models: the filter model (Broadbent, 1958), which assumes that there is no semantic processing of unattended stimuli and which is also contradicted by the Eriksen effect, and the attention-and-priming model (Treisman, 1964), which assumes that unattended stimuli must be primed to be recognized and which is consistent with many previously demonstrated effects of unattended information.

Since the present results contradict the priming assumption but are not inconsistent with early selection or attenuation, it is reasonable to consider early-selection models without the priming assumption. The priming assumption was used by these models to explain why unattended stimuli sometimes had effects in spite of attenuation, so, if that assumption is rejected, how might early-selection models account for effects of unattended stimuli? The most obvious possibility is to assume that attenuation is not very effective, so unattended stimuli receive considerable processing, though less than attended ones. The problem with this view is to explain why, if they are only slightly attenuated, unattended stimuli sometimes do not have any effect at all. To answer this question, it is necessary to examine such null effects carefully.

Most of the null effects of unattended stimuli reflect subjects' inability to describe or recognize unattended stimuli even after many presentations. For example, Morton (1967) showed that people cannot tell how the letters on a telephone dial are laid out, in spite of thousands of exposures. Turvey (1967) presented one particular display repeatedly in a partial-report paradigm (Sperling, 1967), but subjects did not improve at reporting it (but see Besner, Keating, Cake, \& Maddigan, 1974, for a failure to replicate). Neisser and Becklen (1975) and Becklen and Cervone (1983) had subjects attend to one of two episodes on a video display, and found that the subjects rarely noticed unusual events in the unattended episode. Rock and Gutman (1981) showed subjects superimposed forms and asked them to rate one for pleasingness. In a later recognition test, subjects were no better than chance at picking out the unattended forms they had seen from among distractors with the same visual characteristics (see also Rock, Schauer, \& Halper, 1976).

For a variety of reasons, these studies do not invalidate the claim that unattended stimuli receive considerable semantic processing even though they have been attenuated (Kellogg, 1980). First, especially with visual stimuli, the lack of processing for unattended stimuli may in some experiments be caused by differences in sensory rather than attentional processing. Loftus (1972) found that a decrease in recall for unattended, as compared with attended, pictures could be accounted for entirely by differences in the number of fixations on each picture. Second, unattended material is sometimes remembered in paradigms similar to these (e.g., Besner et al., 1974; Goldstein \& Fink, 1981; Kellogg, 1980; Rollins \& Thibadeau, 1973; Wolford \& Morrison, 1980). If subjects sometimes recall the unattended material, then they must have processed it, and these results suggest that ex- periments finding null effects may have been insensitive in some way. Third, there is often some minimal recall of the unattended material even in studies cited in support of very good attentional selection. For example, a few subjects could reproduce the telephone dial in Morton's (1967) study. Becklen and Cervone (1983) found that about $20 \%$ of their subjects could later report an unusual event in the unattended episode. Even if $20 \%$ is a surprisingly small number, it is large enough to be consistent with attenuation rather than filtering notions of attentional selection. Rock and his collaborators (Rock \& Gutman, 1981; Rock et al., 1976) found that unattended pictures were recognized from among visually dissimilar foils, so some processing had taken place. Fourth, studies of both amnesics and normals have shown that quite a lot of learning can take place in the absence of recall and recognition (e.g., Cohen \& Squire, 1980; Eich, 1984; Graf \& Mandler, 1984; Jacoby \& Dallas, 1981; Kellogg, 1980; Marcel, 1983). Recognition and recall may be very insensitive measures of some types of learning, and it may be necessary to look for effects of unattended stimuli using more indirect measures (Marcel, 1983).

The one study that seems most inconsistent with the view that early selection merely attenuates, rather than filters, unattended stimuli was reported by Francolini and Egeth (1980). Subjects were instructed to report the number of red letters presented around a circle, and black digits were interspersed among the red letters. The names of the black digits were either compatible with the required response (e.g., black $4 \mathrm{~s}$ interspersed among four red letters) or incompatible with it (e.g., black 5s interspersed among four red letters). Response compatibility of the digits had no effect, suggesting that selection was perfect. This result is problematic for the view that unattended items receive considerable processing and that effects of this processing can be observed with indirect measures, and I cannot explain it. Note, however, that this result is also inconsistent with the other models considered here. The attenuation-and-priming model would have predicted a compatibility effect of the unattended items, since digit identities would be primed by the response demands of the task. Moreover, late-selection models would also predict a compatibility effect.

\section{Remaining Options for \\ Early-Selection Models}

Although the present results indicate that early-selection models cannot be reconciled with the Eriksen effect by means of an appeal to priming, other possible reconciliations exist. It has been suggested (e.g., Broadbent, 1982) that the Eriksen effect simply reveals limitations of the physical resolution of the selective mechanism (Broadbent, 1982). That is, early selection could be the norm, but such selection could be impossible when relevant and irrelevant items are in close proximity. Consistent with this view, B. A. Eriksen and C. W. Eriksen (1974) found that the effect disappears when the spatial separation between target and flankers increases beyond about $1^{\circ}$. Using related paradigms, C. W. Eriksen and Hoffman (1972, 
1974) and C. W. Eriksen and St. James (1986) also found evidence that selectivity is improved when relevant and irrelevant letters are separated by more than about $1^{\circ}$.

Some other evidence is not congenial to this view, however. Gatti and Egeth (1978) pointed out that as flankers are spatially separated from the target, they also move farther from foveal vision. Thus, increasing separation might eliminate the effect of flankers because they are not perceived in the first place rather than because they are more efficiently removed by an early selection mechanism. Egeth (1977) reported evidence of selectivity failures beyond $1^{\circ}$ when acuity decreases were compensated by increases in stimulus size. ${ }^{5}$ Gatti and Egeth (1978) also found imperfect selectivity with unattended stimuli $5^{\circ}$ from the attended stimulus, although the effect was obtained with Stroop- rather than Eriksen-type interference. Finally, Harms and Bundesen (1983) found that the Eriksen effect does not decrease when an additional color cue is given to aid the selective process, which suggests that imperfect selectivity is not caused by low sensory resolution.

Another possible reconciliation of the Eriksen effect with early-selection models might postulate that selection is indeed early but takes place only when the information processing system is overloaded with too many stimuli to process at once. In the Eriksen task, there are only three letters in the display and early selection might not take place because these letters can all be processed in parallel.

\section{Comparing Effects of Attended and Unattended Stimuli}

Besides looking for identity effects of unattended stimuli, another approach to the problem of discriminating between early- and late-selection models is to see whether unattended stimuli receive the same perceptual processing as do attended stimuli, since late-selection models assume that they do (e.g., Duncan, 1980) but early-selection models assume that they do not (e.g., Kahneman \& Treisman, 1984). To address this question, one has to make a direct comparison of the effects of the two kinds of stimuli. For example, Johnston and Dark (1982) compared the abilities of attended and unattended spoken words to influence the interpretation of an ambiguous word presented visually. They found that attended words did produce greater priming effects than did unattended words, and they concluded that unattended stimuli are attenuated early in processing. Many others have reached the same conclusion on the basis of the finding that unattended stimuli elicit smaller physiological responses than do attended stimuli (e.g., Eason, Harter, \& White, 1969; Fuster \& Jervey, 1981; Goldberg \& Wurtz, 1972; Hillyard, 1984; Van Voorhis \& Hillyard, 1977; Wastell \& Kleinman, 1980). Further research is now in progress to compare the correlational cuing effect obtained with letters in attended and unattended display positions. If the attenuation assumption is correct, the effect should be larger for letters in attended positions. Unfortunately, this approach does not provide a critical test between models, because an extra effect for attended, as opposed to unat- tended, stimuli could result from extra postidentification processing, even if processing of attended and unattended stimuli is equivalent through the point of identification.

\section{Correlational Cuing as a Potential \\ Artifact in Other Studies}

The demonstration of a correlational cuing effect raises the very practical issue that this effect may have been a confounding factor that contributed to effects observed in previous experiments. For example, in the paradigm used by C. W. Eriksen and his associates (e.g., C. W. Eriksen \& Schultz, 1979), the presence of a particular target letter in the display, ignoring position, has been a valid cue as to the correct response. Although the response was independent of the identity of the letter in the flanker positions, the presence of a certain target identity anywhere in the display was still correlated with the response, because of the many trials on which that target appeared in the relevant center position. Overall, when that particular target letter was present somewhere in the display, the response associated with that target was correct more often than not. Perhaps, then, a target cues a response not only because it is a target, but also because the presence of its identity is correlated with that response. If such a response correlation contributes to the previously reported response-compatibility effects, then these effects may not arise entirely in the process that associates targets with responses, as generally assumed.

Correlational cuing may also have contributed to the effects of distractors on RT in yes-no visual search tasks (see Grice, Canham, \& Boroughs, 1984), if nontarget identities acquire the power to activate the negative response because of a frequency correlation with that response. With more distractor items in the display, the negative response might receive more activation because of correlational cuing. This would speed negative responses when they were correct, but would slow positive responses when a target was present. Overall, these effects would increase the slope of the function relating RT to display size for positive responses and decrease it for negative responses. Thus, these slopes might not reflect only the visual search processes, as is generally assumed. Such a confounding may account for some failures to get the $2 / 1$ slope ratio expected from self-terminating search models (e.g., Atkinson, Holmgren, \& Juola, 1969).

\section{Comparison of Correlational Cuing with Other Cuing Manipulations}

Cuing has been used to study various kinds of priming and preparatory processes, including those involving attention (e.g., LaBerge, 1973; Posner, Snyder, \& Davidson, 1980), semantic memory (e.g., Meyer, Schvaneveldt, \& Ruddy, 1974), and the organization of motor responses (e.g., Rosenbaum, 1983; Rosenbaum \& Kornblum, 1982). Cuing studies may be divided into two basic classes, depending on whether the cue is primarily correlated with a property of the stimulus or a property of the response. The present correlational cuing manipulation falls into the second class, because the operative vari- 
able seems to be the correlation of cue identity and response.

The distinction between stimulus- and responsecorrelated cues may help explain why the present studies found a cuing effect with simultaneous presentation of cue and test stimulus, even though some previous studies have found that as much as $\mathbf{4 0 0} \mathrm{msec}$ must intervene between cue and test stimulus for the cue to have any effect (e.g., Neely, 1977). When a cue is correlated with the response, it can affect RT by influencing response processes. Such an effect could develop during processing of the test stimulus if both test stimulus and cue could be processed in parallel. Thus, a cue need not necessarily be presented in advance of the test stimulus to produce an effect on response processes.

However, when a cue is correlated with the test stimulus, it will most likely affect RT by influencing the perceptual processing of that test stimulus. Especially if the cue and test stimulus are arbitrarily related (Neely, 1977), it could take considerable time for information about the cue to have an impact on the perceptual processing of the test stimulus. Thus, it seems logical that a cue would have to be presented sooner, relative to the test stimulus, when it is correlated with the stimulus than when it is correlated with the response.

\section{Implications for Models of Learning}

Because the theoretical focus of this paper has been on selective attention, the implications of the correlational cuing effect for theories of practice effects and learning in general have been largely ignored to this point. The most obvious implication is that there are problems with two-stage learning theories in which the subject first attends to a certain set of stimuli and then "those stimuli and no others are available for association" (Mackintosh, $1975 ;$ p. 227). Evidence in favor of such two-stage theories has come exclusively from tests that rely on conscious manifestations of learning, and such tests may fail to reveal other types of learning that can occur.

In the context of traditional literature on the formation of stimulus-response (S-R) associations, the correlational cuing effect is interesting for several reasons. First, it seems to be an exception to the phenomenon of blocking, in which an $S_{2}-R$ relationship is not learned if an $S_{1}-R$ relationship has already been established and $S_{1}$ and $S_{2}$ are presented redundantly (Mackintosh, 1983). In this case, the exception may come about because the association of flanker and response begins to be formed before the target-response association is overlearned. Second, the correlational cuing effect resembles classical conditioning in that it reflects the buildup of an S-R association with a stimulus that neither causes the response nor signals reinforcement-the target and feedback take care of these functions. From this point of view, the surprising thing is that the unconditioned stimulus (US; i.e., the target) is arbitrarily defined for the subject, whereas the usual US is a biologically potent stimulus like a puff of air to the eye or an electric shock. Indeed, if the correlational cuing effect could be obtained with a varied target set, there would be no consistent US at all. Obviously, the important association in correlational cuing is that between conditioned stimulus (CS) and response, not CS and US, contrary to current belief about classical conditioning (e.g., Bindra, 1972; Dawson, Schell, Beers, \& Kelly, 1982). Perhaps the correlated flankers should be considered to be constant contextual stimuli (Asratyan, 1969) - constant features of the environment that come to produce tonic conditioned responses.

From a more cognitive perspective, the learning underlying the correlational cuing effect also seems to have implications about how practice strengthens $S-R$ associations. In particular, the effect shows that buildup of $S-R$ associations does not require a causal connection between the stimulus and the response. Such a principle does not seem to be embodied in current models of practice effects and the development of automaticity (e.g., Schneider \& Shiffrin, 1977).

The effects of response-correlated cues on RT may also provide an indirect measure of incidental learning that is more sensitive than measures based on conscious awareness (cf. Marcel, 1983). Many studies of learning without awareness were conducted in the late 1950s and early 1960s (e.g., Greenspoon, 1955), and the preponderance of evidence suggested that true learning without awareness does not occur (e.g., C. W. Eriksen \& Doroz, 1963). However, most of these studies sought to document effects of incidental, unnoticed cues on verbal choice behavior. It is possible that the extent of learning without awareness is not sufficient to change the identities of responses, but is sufficient to influence their latencies.

\section{REFERENCES}

Alloy, L. B., \& TABACHNIK, N. (1984). Assessment of covariation by humans and animals: The joint influence of prior expectations and current situational information. Psychological Review, 91, 112-149. Asratyan, E. A. (1969). Classical conditioning research and theories. In M. Cole \& I. Maltzman (Eds.), A handbook of contemporary Soviet psychology (pp. 763-784). New York: Basic Books.

Atrinson, R. C., Holmgren, J., JuolA, J. F. (1969). Processing time as influenced by the number of elements in a visual display. Perception \& Psychophysics, 6, 321-326.

Becklen, R., Cervone, D. (1983). Selective looking and the noticing of unexpected events. Memory \& Cognition, 11, 601-608.

Besner, D., Keating, J. K., Cake, L. J., Maddigan, R. (1974). Repetition effects in iconic and verbal short-term memory. Journal of Experimental Psychology, 102, 901-903.

Biederman, I., \& StaCy, E. (1974). Stimulus probability and stimulus set size in memory scanning. Joumal of Experimental Psychology, 102, 1100-1107.

BINDRA, D. (1972). A unified account of classical conditioning and operant conditioning. In A. H. Black \& W. F. Prokasy (Eds.), Classical conditioning II. Current research and theory (pp. 453-481). New York: Appleton-Century-Crofts.

BroAdbent, D. E. (1958). Perception and communication. London: Pergamon Press.

Brondbent, D. E. (1971). Decision and stress. London: Academic Press.

BrondBent, D. E. (1982). Task combination and selective intake of information. Acta Psychologica, 50, 253-290.

Cohen, N. J., SQuIre, L. R. (1980). Preserved learning and retention of pattern-analyzing skill in amnesia: Dissociation of knowing how and knowing that. Science, 210, 207-210. 
Coles, M. G. H., Gratton, G., Bashore, T. R., Eriksen, C. W., \& Donchin, E. (1985). A psychophysical investigation of the continuous flow model of human information processing. Journal of Experimental Psychology: Human Perception \& Performance, 11 , 529-553.

CorteEn, R. S., \& Wood, B. (1972). Autonomic responses to shock associated words in an unattended channel. Journal of Experimental Psychology, 97, 308-313.

Dalrymple-Alford, E. C., \& Azkoul, J. (1972). The locus of interference in the Stroop and related tasks. Perception \& Psychophysics, 11, 385-388.

DAwSON, M., \& SCHELL, A. (1982). Electrodermal responses to attended and nonattended significant stimuli during dichotic listening. Journal of Experimental Psychology: Human Perception \& Performance, 8, 315-324.

Dawson, M., Schell, A., Beers, J., \& Kelly, A. (1982). Allocation of cognitive processing capacity during human autonomic classical conditioning. Journal of Experimental Psychology: General, 111, 273-295.

Deutsch, J. A., \& Deutsch, D. (1963). Attention: Some theoretical considerations. Psychological Review, 70, 80-90.

DUNCAN, J. (1980). The locus of interference in the perception of simultaneous stimuli. Psychological Review, 87, 272-300.

DYKES, J., \& PASCAL, V. (1981). The effect of stimulus probability on the perceptual processing of letters. Journal of Experimental Psychology: Human Perception \& Performance, 7, 528-537.

Eason, R., HARTER, R., \& WHTE, C. (1969). Effects of attention and arousal on visually evoked cortical potentials and reaction time in man. Physiology \& Behavior, 4, 283-289.

EgETH, H. E. (1967). Selective attention. Psychological Bulletin, 67, 41-57.

EGETH, H. E. (1977). Attention and preattention. In G. Bower (Ed.), The psychology of leaming and motivation (Vol. 2, pp. 277-320). New York: Academic Press.

EICH, E. (1984). Memory for unattended events: Remembering with and without awareness. Memory \& Cognition, 12, 105-111.

ERIKSEN, B. A., \& ERIKSEN, C. W. (1974). Effects of noise letters upon the identification of a target letter in a nonsearch task. Perception \& Psychophysics, 16, 143-149.

ERIKSEN, C. W., Doroz, L. (1963). Role of awareness in learning and use of correlated extraneous cues on perceptual tasks. Journal of Experimental Psychology, 66, 601-608.

ErIKsen, C. W., HoffMAN, J. (1972). Temporal and spatial characteristics of selective encoding from visual displays. Perception \& Psychophysics, 12, 201-204.

ERIKSEN, C. W., \& HofFMAN, J. (1974). Selective attention: Noise suppression or signal enhancement? Bulletin of the Psychonomic Society, 4, 587-589.

ERIKSEN, C. W., \& ST. JAmes, J. D. (1986). Visual attention within and around the field of focal attention: A zoom lens model. Perception \& Psychophysics, 40, 225-240.

ERIKSEN, C. W., SChultz, D. W. (1979). Information processing in visual search: A continuous flow conception and experimental results. Perception \& Psychophysics, 25, 249-263.

EsTES, W. K. (1982). Similarity-related channel interactions in visual processing. Journal of Experimental Psychology: Human Perception \& Performance, 8, 353-382.

Forster, P. M., Govier, E. (1978). Discrimination without awareness? Quarterly Joumal of Experimental Psychology, 30, 289-295.

Francoluni, C. M., EGETH, H. E. (1980). On the nonautomaticity of "automatic" activation: Evidence of selective seeing. Perception \& Psychophysics, 27, 331-342.

Fuster, J. M., \& JERVEY, J. P. (1981). Inferotemporal neurons distinguish and retain behaviorally relevant features of visual stimuli. Science, 212, 952-955.

GATT, S. V., EGETH, H. E. (1978). Failure of spatial selectivity in vision. Bulletin of the Psychonomic Society, 11, 181-184.

GolDBERG, M. E., \& WuRTZ, R. (1972). Activity of superior colliculus in behaving monkeys: II. Effects of attention on neuronal response. Journal of Neurophysiology, 35, 560-574.
GoldDTEIN, E., \& Fink, S. (1981). Selective attention in vision: Recognition memory for superimposed line drawings. Joumal of Experimental Psychology: Human Perception \& Performance, 7, 954-967.

Govier, E., PITTS, M. (1982). The contextual disambiguation of a polysemous word in an unattended message. British Journal of Psychology, 73, 537-545.

Graf, P., \& Mandler, G. (1984). Activation makes words more accessible, but not necessarily more retrievable. Journal of Verbal Leaming \& Verbal Behavior, 23, 553-568.

GREENE, R. L. (1984). Incidental learning of event frequency. Memory \& Cognition, 12, 90-95.

GREENSPOON, J. (1955). The reinforcing effect of two spoken sounds on the frequency of two responses. American Journal of Psychology, 68, 409-416.

Grice, G. R., Canham, L., \& Boroughs, J. M. (1984). Combination rule for redundant information in reaction time tasks with divided attention. Perception \& Psychophysics, 35, 451-463.

Harms, L., \& BUNDESEN, C. (1983). Color segregation and selective attention in a nonsearch task. Perception \& Psychophysics, 33, 11-19.

HASHeR, L., \& ZACKS, R. T. (1979). Automatic and effortful processes in memory. Joumal of Experimental Psychology: General, 108, 356-388.

HASHER, L., \& ZACKs, R. T. (1984). Automatic processing of fundamental information: The case of frequency of occurrence. American Psychologist, 39, 1372-1388.

HAwkINS, R. D. (1983). Cellular neurophysiological studies of learning. In J. A. Deutsch (Ed.), The physiological basis of memory (pp. 71-120). New York: Academic Press.

HILLYARD, S. A. (1984). Event-related potentials and selective attention. In E. Donchin (Ed.), Cognitive psychophysiology: Event-related potentials and the study of cognition: The Carmel Conferences (Vol. 1, pp. 51-72). Hillsdale, NJ: Erlbaum.

JACOBY, L. L., \& DALLAS, M. (1981). On the relationship between autobiographical memory and perceptual learning. Journal of Experimental Psychology: General, 110, 306-340.

James, W. (1890). Principles of psychology. New York: Holt.

Johnston, W., \& DARK, V. (1982). In defense of intraperceptual theories of attention. Journal of Experimental Psychology: Human Perception \& Performance, 8, 407-421.

Kahneman, D., Treisman, A. (1984). Changing views of attention and automaticity. In R. Parasuraman \& D. R. Davies (Eds.), Varieties of attention (pp. 29-61). New York: Academic Press.

KELLOGG, R. T. (1980). Is conscious attention necessary for long term storage? Journal of Experimental Psychology: Human Leaming \& Memory, 6, 379-390.

LABERGE, D. (1973). Identification of two components of the time to switch attention: A test of a serial and a parallel model of attention. In. S. Kornblum (Ed.), Attention and performance (Vol. 4, pp. 71-85). New York: Academic Press.

LACKNER, J. R., \& GARRETT, M. F. (1972). Resolving ambiguity: Effects of biasing context in the unattended ear. Cognition, 1, 359-372.

LEWIS, J. L. (1970). Semantic processing of unattended messages using dichotic listening. Joumal of Experimental Psychology, 85, 225-228.

LofTus, G. R. (1972). Eye fixations and recognition memory for pictures. Cognitive Psychology, 3, 525-551.

LOGAN, G. D., \& ZBRoDoFF, N. J. (1979). When it helps to be misled: Facilitative effects of increasing the frequency of conflicting stimuli in a Stroop-like task. Memory \& Cognition, 7, 166-174.

MACKAY, D. G. (1973). Aspects of the theory of comprehension, memory and attention. Quarterly Journal of Experimental Psychology, 25, 22-40.

MACKINTOSH, N. J. (1975). A theory of attention: Variations in the associability of stimuli with reinforcement. Psychological Review, 82, 276-298.

MACKINTOSH, N. J. (1983). Conditioning and associative leaming. New York: Oxford University Press.

MARCEL, A. J. (1983). Conscious and unconscious perception: An approach to the relations between phenomenal experience and perceptual processes. Cognitive Psychology, 15, 238-300.

MCClelland, J. L., \& RumelharT, D. E. (1985). Distributed memory 
and the representation of general and specific information. Journal of Experimental Psychology, 114, 159-188.

MeYer, D. E., SchvaneVeldt, R. W., \& Ruddy, M. G. (1974). Functions of graphemic and phonemic codes in visual word-recognition. Memory \& Cognition, 2, 309-321.

Miller, J. O. (1979). Cognitive influences on perceptual processing Journal of Experimental Psychology: Human Perception \& Performance, 5, 545-562.

MiLLeR, J. O. (1982). Divided attention: Evidence for coactivation with redundant signals. Cognitive Psychology, 14, 247-279.

Miller, J. O., \& BAUER, D. W. (1981). Visual similarity and discrimination demands. Journal of Experimental Psychology: General, 110, 39-55.

Miller, J. O., \& Pachella, R. G. (1973). On the locus of the stimulus probability effect. Journal of Experimental Psychology, 101, 227-231.

MoRTON, J. (1967). A singular lack of incidental learning. Nature, 215, 203-204.

MORTON, J. (1969). Interaction of information in word recognition. Psychological Review, 76, 165-178.

NeELY, J. H. (1977). Semantic priming and retrieval from lexical memory: Roles of inhibitionless spreading activation and limitedcapacity attention. Joumal of Experimental Psychology: General, 106, 226-254.

NeISSER, U. (1967). Cognitive psychology. New York: AppletonCentury-Crofts.

NeIsSER, U. (1979). The control of information pickup in selective looking. In A. D. Pick (Ed.), Perception and its development: A tribute to Eleanor J. Gibson (pp. 201-219). Hillsdale, NJ: Erlbaum.

NeISSER, U., BeCKLEN, R. (1975). Selective looking: Attending to visually specified events. Cognitive Psychology, 7, 480-494.

Ostry, D., Moray, N., \& MARKs, G. (1976). Attention, practice, and semantic targets. Joumal of Experimental Psychology: Human Perception \& Performance, 2, 326-336.

PosNer, M. I. (1973). Coordination of internal codes. In W. G. Chase (Ed.), Visual information processing (pp. 35-73). New York: Academic Press.

Posner, M. I., Cohen, Y., Chonte, L. S., Hockey, R., \& MayLOR, E. (1984). Sustained concentration: Passive filtering or active orienting? In S. Kornblum \& J. Requin (Eds.), Preparatory states and processes (pp. 49-65). Hillsdale, NJ: Erlbaum.

PosNer, M. I., \& SNYDER, C. (1975). Facilitation and inhibition in the processing of signals. In P. M. A. Rabbitt \& S. Dornic (Eds.), Attention and performance (Vol. 5, pp. 669-682). New York: Academic Press.

Posner, M. I., Snyder, C., \& Davidson, B. (1980). Attention and the detection of signals. Joumal of Experimental Psychology: General, 109, 160-174.

PROCTOR, R. W. (1978). Sources of color-word interference in the Stroop color-naming task. Perception \& Psychophysics, 23, 413-419.

Rock, I., \&UTMAN, D. (1981). The effect of inattention on form perception. Journal of Experimental Psychology: Human Perception \& Performance, 7, 275-285.

ROCK, I., SCHAUER, R., \& HALPER, F. (1976). Form perception without attention. Quarterly Journal of Experimental Psychology, 28, 429-440.

Rollins, H. A., * Thibadeau, R. (1973). The effects of auditory shadowing on recognition of information received visually. Memory \& Cognition, 1, 164-168.

Rosenbaum, D. A. (1983). The movement precuing technique: Assumptions, applications, and extensions. In R. A. Magill (Ed.), Memory and control of action (pp. 231-274). Amsterdam: North Holland.

Rosenbaum, D. A., \& Kornblum, S. (1982). A priming method for investigating the selection of motor responses. Acta Psychologica, 51 , 223-243.

SCHNEIDER, W., \& SHIFFrN, R. M. (1977). Controlled and automatic human information processing: I. Detection, search, and attention. Psychological Review, 84, 1-66.

SEAMON, J. G., \& WRIGHT, C. E. (1976). Generative processes in character classification: Evidence for a probe encoding set. Memory \& Cognition, 4, 96-102.
Shiffrin, R. M. (1975). The locus and role of attention in memory systems. In P. M. A. Rabbitt \& S. Dornic (Eds.), Attention and performance (Vol. 5, pp. 168-193). New York: Academic Press.

SHIFFrin, R. M., \& SchneIder, W. (1977). Controlled and automatic human information processing: II. Perceptual learning, automatic attending, and a general theory. Psychological Review, 84, 127-190.

Silver, D. S., SAltz, E. , Modiglana, V. (1970). Awareness and hypothesis testing in concept and operant learning. Journal of Experimental Psychology, 84, 198-202.

Simon, J. R., Acosta, E., Mewaldt, S. P., \& SPeidel, C.R. (1976). The effect of an irrelevant directional cue on choice reaction time: Duration of the phenomenon and its relation to stages of processing. Perception \& Psychophysics, 19, 16-22.

SPERLING, G. (1967). Successive approximations to a model for shortterm memory. Acta Psychologica, 27, 285-292.

STroop, J. R. (1935). Studies of interference in serial verbal reactions. Journal of Experimental Psychology, 18, 643-662.

Treisman, A. M. (1964). Monitoring and storage of irrelevant messages in selective attention. Joumal of Verbal Leaming \& Verbal Behavior, 3, 449-459.

TURVEY, M. T. (1967). Repetition and the preperceptual information store. Journal of Experimental Psychology, 74, 289-293.

UNDERWOOD, G. (1976). Semantic interference from unattended printed words. British Journal of Psychology, 67, 327-338.

VAN DER Heuden, A. H. C. (1981). Short-term visual information forgetting. London: Routledge \& Kegan Paul.

VAN Voorhis, S., \&ILlyard, S. (1977). Visual evoked potentials and selective attention to points in space. Perception \& Psychophysics, 22, 54-62.

WASTELL, D. G., \& KLEINMAN, D. (1980). Evoked potential correlates of visual selective attention. Acta Psychologica, 46, 129-140.

Wolford, G. L., \& MORRISON, F. (1980). Processing of unattended visual information. Memory \& Cognition, 8, 521-527.

YEH, Y. Y., \& ERIKSEN, C. W. (1984). Name codes and features in the discrimination of letter forms. Perception \& Psychophysics, 36, 225-233.

\section{NOTES}

1. Although this paper focuses on the Eriksen paradigm, analogous arguments could be made using the closely related Stroop (1935) paradigm.

2. Following Morton (1969), the term "logogens" will be used to refer to those components of the semantic analysis system whose activation corresponds to recognition of individual letters. This usage is not intended to prejudge the nature of the internal representation of these components (cf. McClelland \& Rumelhart, 1985).

3. There is evidence of the importance of priming in the Stroop task, but it is not clear that the effect is related to the efficiency of selective attention. A number of experiments have found larger Stroop interference for color words included in the set of color responses in the task than for other color words (e.g., Dalrymple-Alford \& Azkoul, 1972; Proctor, 1978). Although this effect may be due to priming of the words used as responses, it is not clear whether the priming causes response words to be identified and others not, or whether all words are identified and the priming causes response words to produce more competition. Only the former possibility would be consistent with early-selection models that assume attenuation and priming.

4. This aspect of the experiment was suggested by Kirsten Schreiner.

5. C. W. Eriksen (personal communication, November 1986) pointed out, however, that increasing flanker size introduces a new factor that may also be important. Namely, there may be a natural tendency to pay more attention to stimuli that are larger. Thus, this evidence of selectivity failure may not have been caused by adequate acuity, but rather by attentional selection of large stimuli.

(Manuscript received September 26, 1986; revision accepted for publication January $14,1987$. ) 